\title{
Comparative Study of Antimicrobial Effectiveness of SPI- Cinnamaldehyde Composite Films as Process Variety of Casting and Coating and Application
}

\author{
Ki Myong $\mathrm{Kim}^{1} *$ \\ ${ }^{1}$ Department of Food \& Nutrition, Honam University, Gwangju Republic of \\ Korea, \\ *Corresponding author: Ki Myong Kim, Department of Food \& Nutrition, \\ Honam University, Eudeung Daero 417, Gwangsan gu, Gwangju, Republic of \\ Korea, 506-714
}

\begin{abstract}
Comparative investigation of the antimicrobial effectiveness of cinnamaldehyde incorporated soy protein isolate (SC) films and cinnamaldehyde-SPI coated polypropylene/polypropylene (SC/OPP/PE) films were investigated. Minimum inhibitory and minimum bactericidal concentrations (MIC, MBC) of cinnamaldehyde against Escherichia coli, Salmonella typhymurium, Bacillus cereus, and Enterobacter sakazakii were investigated. Addition of cinnamaldehyde into SPI increased the tensile strength, whereas decreased the water vapor permeability and elongation at film breakage. Size of antimicrobial zone in disc diffusion test was decreased in cast films and no diffusion was found in coated OPP/PE films but concentration dependently deduction of total microbial count was found when three different sprouts (radish, broccoli, alfalfa) were packed with CASPI-OPP/PE film by pouch type. It indicated that cinnamaldehyde with low concentration could diffuse to environment and could be effective on antimicrobial for preservation of food packaging.
\end{abstract}

Keywords: Cinnamaldehyde, sprout, shelf-life, antimicrobial packaging

\section{Introduction}

Since quality and safety are major concerns related to food products, many kinds of preservatives are added to prevent spoilage and maximize consumer safety (1). Natural preservatives with antimicrobial activity such as spices, essential oils, and oleoresins have been incorporated into food or packaging materials to improve antimicrobial effectiveness. However, direct application of antimicrobials to food may not necessarily be effective since the active compounds may evaporate or be rapidly neutralized (2). As an alternative, packaging material that incorporates antimicrobial compounds retain their potency for an extended period can inhibit or retard the growth of spoilage and pathogenic microorganisms $(3,4)$. Most naturally derived antimicrobials are volatile compounds that are sensitive to heat. Therefore, use of a solvent or incorporation of the compound into a polymer will be more effective in antimicrobial film preparation. Antimicrobials that cannot tolerate the temperatures used in polymer processing can be coated onto the packaging materials using polymers as carriers (1). Biopolymers such as polysaccharides, proteins, and lipids can be used as film forming materials or carriers (5). However, it has been proved that effectiveness of the antimicrobial compounds reduced when they were incorporated into the film forming materials due to the dispersion effect of the active compounds and the interactions among compounds of the film forming material $(6,7)$. Although proteins can be used as edible and biodegradable film forming materials, they present a poor moisture barrier due to their hydrophilic nature (6). Many studies have 
focused on improving the functional properties of biopolymer films. Aldehyde crosslinking in soy protein improves film properties resulting increased tensile strength (TS), percent elongation at break (E \%), and decreased water vapor permeability (WVP) (8). However, the toxic nature of some low molecular aldehydes such as formaldehyde prevents their use in films and coatings. Cinnamaldehyde is a small compound (Mw 132.15) that is comparatively non-toxic compared to other aldehydes; it is used as a food grade additive and is an effective cross-linking agent (9). The antimicrobial activity of cinnamaldehyde against bacteria, fungi, and molds has been confirmed $(2,4,11$, and 12).

Fresh or minimally processed foods particularly vegetables are popular with consumers. The number and type of microorganisms found on such produce are highly variable; for example, the number of viable mesophilic bacteria per $g$ ranges from $10^{3}-10^{9}(13)$. The extent of microbial propagation on produce depends primarily on the morphological and physiological condition of the plant tissue. Physiologically damaged tissues tend to deteriorate more rapidly, which encourages microbial growth (13). In the packaging of sprouts, minimal processing is practiced and plant tissues are damaged causing higher respiration and rapid spoilage. The number of total aerobic mesophilic bacteria, psychrotophic bacteria, and total and fecal coliforms can reach $7-9 \log _{10}$ colony forming units (CFU)/g in alfalfa seeds (14) and broccoli and radish sprouts (15) after five days of germination. Availability of nutrients and moisture, and favorable temperature during germination contributes the rapid growth of microbes causing foodborne diseases as well as reducing the shelf life of sprouts (16). Antimicrobial coated films may be an efficient alternative to prevent microbial growth leading to spoilage of sprouts since the active ingredient may selectively and gradually migrate from the package to the head space for a extended period of time (17).

The objectives of the present study were to evaluate and comparative investigation of the antimicrobial effectiveness of cinnamaldehyde incorporated soy protein isolate (SPI) films and cinnamaldehyde-SPI coated packaging films and to evaluate the utility of those films in prolonging the shelf life of alfalfa, broccoli, and radish sprouts.

\section{Materials and Method}

Materials. Trans-cinnamaldehyde was obtained from Sigma-Aldrich (St. Louis, MO, USA). Muller Hinton Broth (MHB), Trypticase Soy Agar (TSA), and Plate Count Agar (PCA) were obtained from Difco Laboratories (Detroit, MI, USA). SPI powder (Supro® IP) was purchased from Du Pont (New York, NY, USA). Oriented polypropylene/polypropylene (OPP/PE) films were provided by Sammin F \& FP (Seoul, Korea). Radish, broccoli, and alfalfa sprouts were purchased from Sangsoo's Herb, Chung-buk, Korea.

Bacterial cultures. Stock cultures of Escherichia coli O157:H7 (KCTC 2441), Bacillus cereus (KCTC 1012), and Enterobacter sakazakii (KCTC 2949) were obtained from the Korean Collection for Type Cultures. Salmonella typhimurium (KCCM 11806) was obtained from the Korean Culture Centre of Microorganisms. All cultures were maintained on TSA slants at $4^{\circ} \mathrm{C}$. A loop full of bacteria culture was transferred into TSB and incubated at $37^{\circ} \mathrm{C}$ for $24 \mathrm{~h}$. After smearing a recovered aliquot on TSA and incubation for a further $24 \mathrm{~h}$ at $37^{\circ} \mathrm{C}$ a single colony that developed was transferred to $10 \mathrm{~mL}$ of TSB and incubated at $37^{\circ} \mathrm{C}$ for $24 \mathrm{~h}$. This culture was used for further experiments.

Antimicrobial activities of antimicrobial compounds. The inhibitory effects of transcinnamaldehyde against the selected E. coli, S. typhimurium, B. cereus, and E. sakazakii isolates were determined by the modified agar disc diffusion method (18). A single colony from each bacterial strain was transferred to $10 \mathrm{~mL}$ TSB and incubated overnight. One microliter of each resulting culture was inoculated on TSA. Cinnamaldehyde was diluted with distilled water to prepare $\mathrm{v} / \mathrm{v}$ concentrations of $0.1,0.2,0.3,0.4,0.5$, and $0.6 \%$. Tween-20 $(0.3 \%$, w/v in distilled water) was added as an emulsifier to enhance the 
solubility of the compounds in distilled water prior to homogenization at $11000 \mathrm{rpm}$ for 5 min. Aliquots of $50 \mu \mathrm{l}$ were dispensed onto $8 \mathrm{~mm}$ diameter sterile filter paper discs (Advantec, Dublin, CA, USA) twice with air drying in between. Each of the discs was placed on TSA that had been previously seeded with the target bacterial strain and incubated at $37^{\circ} \mathrm{C}$ for $24 \mathrm{~h}$. Inhibitory zones, including the disc diameter were measured using a caliper. Antimicrobial films were also cut into discs (diameter: $8 \mathrm{~mm}$ ) and same method was carried out for antimicrobial test. Minimal inhibitory concentrations (MICs) were determined as previously described (19). Briefly, a single colony from each bacterial culture was separately transferred into a test tube containing TSB and incubated overnight. The optical density (OD) was adjusted to a McFarland standard No. 0.5 using a sterile sodium chloride solution $(8.5 \mathrm{~g} / \mathrm{L})$ to obtain a bacteria concentration of approximately $10^{8}$ $\mathrm{CFU} / \mathrm{mL}$. A final cell concentration of $10^{6} \mathrm{CFU} / \mathrm{mL}$ was obtained by diluting the culture solution 100 times with sterile sodium chloride solution (Duksan Pure Chemical, Gyeonggi-do, Korea). One milliliter of the culture solution was transferred into $1 \mathrm{~mL}$ of Muller Hinton Broth (MHB; Difco) and then $160 \mu \mathrm{l}$ of a prepared cinnamaldehyde concentration was added and incubated at $37^{\circ} \mathrm{C}$ for $24 \mathrm{~h}$. The lowest concentration of cinnamaldehyde that did not permit development of turbidity represented the MIC (18, 20). After determination of the MIC, a $0.1 \mathrm{~mL}$ aliquot from each tube that was determined to be non-turbid and the last tube in which turbidity was evident smeared on TSA and incubated $37^{\circ} \mathrm{C}$ for $24 \mathrm{~h}$. Viable counts were performed. The minimum bactericidal concentration $(\mathrm{MBC})$ represented the lowest concentration at which the initial viable count was reduced by $99.9 \%$ or more $(18,20)$.

Antimicrobial film preparation. SPI-cinnamaldehyde films were prepared as previously described (8). SPI powder $(5 \mathrm{~g})$ was dissolved in $100 \mathrm{~mL}$ distilled water together with $2.5 \mathrm{~g}$ of glycerin as a plasticizer. After adjusting the $\mathrm{pH}$ of the solution to 10 using $1 \mathrm{~N}$ sodium hydroxide, cinnamaldehyde was added directly to the film forming solution at concentrations of $0.2,0.4,0.6,0.8,1.0$, and $1.2 \%(\mathrm{v} / \mathrm{v})$. Each solution was stirred for $1 \mathrm{~h}$ followed by heating for $15 \mathrm{~min}$ in a water bath at $75^{\circ} \mathrm{C}$ and strained through cheesecloth (Cheesecloth wipes ${ }^{\mathrm{TM}}$; VWP ${ }^{\circledR}$, Chicago, IL, USA). Each solution was cast on leveled Teflon coated glass plates and allowed to dry for 24-36 h at ambient temperature. Dried films were peeled off and conditioned at $50 \%$ relative humidity and $25^{\circ} \mathrm{C}$ for $24 \mathrm{~h}$. SPI coatings were prepared according to a previously described modification of SPI film preparation (9). Coating solutions were prepared by dissolving $10 \mathrm{~g}$ of SPI in $100 \mathrm{~mL}$ of distilled water and $5 \mathrm{~g}$ of glycerin (Sigma Aldrich) as a plasticizer. Sodium hydroxide (1 $\mathrm{N}$; Shinyo Pure Chemicals) was used to adjust the $\mathrm{pH}$ of the coating solution to $10.0 \pm$ 0.01 . Cinnamaldehyde was added directly to the solution at $\mathrm{v} / \mathrm{v}$ concentrations of $0.6,0.8$, 1.0 , or $1.2 \%$. Solutions were stirred for $1 \mathrm{~h}$ and the $\mathrm{pH}$ was adjusted to 10.00 . The solutions were heated for $15 \mathrm{~min}$ in a water bath at $75^{\circ} \mathrm{C}$ and strained through cheesecloth to remove air bubbles and remaining particles. Prepared solutions $(5 \mathrm{~mL})$ were coated manually onto corona treated polyethylene (PE) side surface of OPP/PE films (thickness: $20 \mu \mathrm{m} / 30 \mu \mathrm{m}$, size: $29 \mathrm{~cm} \times 21 \mathrm{~cm}$ ) using a No. 28 coating rod (R.D.S., Webster, NY, USA) and dried in an oven operating at $40^{\circ} \mathrm{C}$ for $30 \mathrm{~min}$. Immediately after removal from the oven the coated side of the films were laminated with linear low density polyethylene (LLDPE) film (thickness: $10 \mu \mathrm{m}$ ) and made into a pouch by heat sealing.

Film properties. Thickness of the film was measured by digital micrometer (ID-C112, Mitutoyo Corp. Japan) to an accuracy of $\pm 1 \mu \mathrm{m}$. Film samples used for WVP tests were measured at five points, one at the center and four from the perimeter. The mean of these measurements was used for WVP calculations. For TS calculations, five thickness measurements were taken and the mean was used. Water vapor permeability (WVP) is the passage of water vapor through the aforementioned film. Water vapor transmission rate (WVTR) was determined by the ASTM gravimetric modified cup method E 90-95 (21). Film specimens were mounted on circular test cups made from polymethylmethacrylate. Distilled water $(10 \mathrm{~mL})$ was placed in the bottom of the test cups to expose the film to a 
high relative humidity inside the cup. The cups were placed inside a chamber set at $25^{\circ} \mathrm{C}$ and 50\% relative humidity. The weight of each cup was recorded six times at $2 \mathrm{~h}$ intervals. Three film specimens from SPI- cinnamaldehyde films and coated films were tested for different concentrations of cinnamaldehyde and the control. Finally, WVP $(\mathrm{g} / \mathrm{m} \cdot \mathrm{h} \cdot \mathrm{Pa})$ was calculated as:

$\mathrm{WVP}=(\mathrm{WVTR} \cdot l) / \Delta \mathrm{p}$

Where WVTR is the water vapor transmission rate $(\mathrm{g} / \mathrm{m} \cdot \mathrm{h})$ through the film specimen, $\boldsymbol{l}$ is the average film thickness (m), and $\Delta \mathrm{p}$ is the partial water vapor pressure difference (Pa) between the two sides of the film specimen. Tensile strength (TS) and elongation at break (E\%) were determined using the Model 5566 Universal Testing Machine (Instron, Canton, MA, USA). Initial grip separation was set at $50 \mathrm{~mm}$ and cross- head speed was set at $500 \mathrm{~mm} / \mathrm{min}$. TS was calculated by dividing the maximum load $(\mathrm{N})$ by the initial cross sectional area $\left(\mathrm{m}^{2}\right)$ of the specimen and expressed in MPa. E\% is the ratio of the final length at the point at break to the initial length of the specimen $(50 \mathrm{~mm})$ expressed as a percentage.

Determination of total microbial count of sprouts. Alfalfa, broccoli, and radish sprouts were separately packed $(30 \mathrm{~g})$ into previously made pouches and heat sealed. The packages were stored at $10^{\circ} \mathrm{C}$ for 5 days; the total microbial number was determined every $24 \mathrm{~h}$.

Sprouts stored in different concentrations of cinnamaldehyde-coated packages as well as the fresh sprouts on arrival were examined for levels of total microbes. Three packages from each treatment were aseptically opened just before testing and the total microbial count in each sprout sample was determined.

From each type of sprouts, $10 \mathrm{~g}$ were aseptically transferred to a sterile stomacher bag (Interscience, France) and $100 \mathrm{~mL}$ of sterile saline water was added. The samples were then homogenized for $1 \mathrm{~min}$ in a stomacher (Interscience, St. Nom, France). A series of decimal dilutions was prepared using $9.0 \mathrm{~mL}$ of sterilized $0.1 \%$ peptone water $(\mathrm{pH} \mathrm{7.0)}$. The total number of microbes in each sample was determined plating $0.1 \mathrm{~mL}$ aliquots of each serially dilution on plate count agar (PLA), incubating for $24-36 \mathrm{~h}$ at $37^{\circ} \mathrm{C}$, and counting the developed colonies. The average number of colonies on the plate was calculated and the results were expressed as $\mathrm{CFU} / \mathrm{g}$.

Statistical analysis. The SAS ver. 9.1 statistical program (SAS, Cary, NC, USA) was used for the statistical analysis and Duncan's multiple range test was done to determine the significance of the treatments.

\section{Results and Discussion}

Antimicrobial activity of cinnamaldehyde. With increasing cinnamaldehyde concentration, the diameter of the growth inhibition zone increased in all tested microorganisms (Table 1). Cinnamaldehyde is well known for its effectiveness against fungi, yeast, and molds, as well as bacteria (22). The antibacterial effect may be a consequence of cinnamaldehyde-mediated inhibition of the production of an essential enzyme or damage to the cell wall of the bacteria (22). The hydrophobic character of cinnamaldehyde enables the separation of lipids in the bacterial cell membrane, disturbing the structure and rendering the membrane more permeable. An electron microscopic study of $S$. aureus documented the disruption of the cytoplasmic membrane with the attendant loss of nucleic acids and ions (19). Cinnamaldehyde concentrations ranging from $0.1 \%$ $0.8 \%(\mathrm{v} / \mathrm{v})$ were used to determine the MIC and MBC against tested bacteria strains. MIC and MBC of cinnamaldehyde against E. coli, S. typhymurium, B. cereus, and E. sakazakii were in the range of $0.1 \%-0.6 \%(\mathrm{v} / \mathrm{v})$ (Table 2). MIC against aforementioned bacteria strains was $0.4 \%$ whereas the MBC was $0.5 \%$ except for E. sakazakii.

Antimicrobial effect of cinnamaldehyde incorporated SPI films and coatings. Even though all concentrations used in the disc diffusion method showed inhibition zones and 
MIC and MBC were within the range of $0.1 \%-0.6 \%(\mathrm{v} / \mathrm{v})$, incorporation of the same concentrations to SPI films did not inhibit any of the tested microorganisms. Several possibilities can be reasoned 1) low concentration for practical use; 2) chemical interaction of cinnamaldehyde; or 3) loss of cinnamaldehyde during long time process. Similar results have been observed by Ponce et al. (7). They have reported that chitosan solutions containing $1 \%$ of different oleoresins (olive, rosemary, garlic, oreganum etc.) showed limited antimicrobial effects against the native micro flora of butternut squash and L. monocytogenes. This may be due to the amount of antimicrobial compounds used for the antimicrobial test may not be sufficient to inhibit the comparatively high number of bacteria in the inoculum $\left(10^{6}-10^{7} \mathrm{CFU}\right)$ and/or the diffusivity of antimicrobial compounds may be hindered when incorporated into the polymer films (6). Aldehydes can promote inter- and intramolecular cross-linking in protein. Amino group, sulfhydryl groups, the imidasole ring of histidine and the phenolic ring of tyrosine have shown the ability to interact with aldehydes. Soy protein is very susceptible to aldehyde-induced cross-linking due to its high content of lysine. The increment of tensile strength of cinnamaldehyde-SPI incorporated films has already proved the cross-linking effect between aldehyde and SPI molecules. This chemical reaction improved the mechanical properties of SPI but in other aspect, decreased its diffusive activity from matrix of SPI to environment. Casting process needed long time till peeling the films from plates. Even under ambient temperature for drying, cinnamaldehyde could evaporate into air resulted in less concentration which was supposed to be contained in films. Seydim and Sarikus (23) reported that antimicrobial activity against different food pathogens was observed when the concentration of oregano, rosemary, and garlic essential oils incorporated into the way protein films were increased from $1 \%$ to $4 \%$. Therefore, we decided to increase the amount of cinnamaldehyde incorporated into the film forming solution to prepare the antimicrobial films and coatings. The cinnamaldehyde concentrations used for further studies ranged from $0.6 \%-1.2 \%(\mathrm{v} / \mathrm{v})$. The antimicrobial properties of cinnamaldehyde incorporated SPI films against the tested microorganisms is shown in table 3. In general, inhibitory activity is measured based on the clear zone surrounding the film discs. Diffusion of the active compound in the film depends on the size, shape, and polarity of the compound itself and chemical structure and level of cross-linking of the film (24). The SPI film without addition of cinnamaldehyde did not show any inhibitory zone against the tested microorganisms. Incorporating cinnamaldehyde into SPI films produced an antimicrobial effect from the incorporated concentration of $0.8 \%$. The area of the inhibitory zones increased with an increasing amount of cinnamaldehyde incorporated into the SPI film. SPI can be used as an efficient carrier for bioactive compounds such as cinnamaldehyde. In addition, it can be used as an excellent coating material on plastic films to produce composite films together with an appropriate plasticizer (25). The antimicrobial effectiveness of the cinnamaldehyde-SPI coated OPP/PE films is shown in table 3 also. Cinnamaldehyde concentrations of $0.8,1.0$, and $1.2 \%$ were able to inhibit the growth of all types of microorganisms underneath the film. This implies that upon contact cinnamaldehyde incorporated SPI coatings can inhibit the growth of tested microorganisms. However, compared to cinnamaldehyde-SPI films, coated films have less antimicrobial activity, as for coating we used only $5 \mathrm{~mL}$ of the cinnamaldehyde-SPI solution. Table 4 clearly shows the effective amount of cinnamaldehyde incorporated SPI films which react as antimicrobial layers. It is revealed that antimicrobial active amount of coating film was as about $1 / 20-1 / 30$ as of SPI/ cinnamaldehyde films in all cinnamaldehyde concentrations. Previous observations described that when cinnamaldehyde incorporated polyamide resin was coated onto LDPE films; about $17 \%$ reduction in final cell concentration of $E$. coli and $15 \%$ reduction in L. innocua were observed (12). 


\section{Antimicrobial effect of cinnamaldehyde coated film on total microbial count of sprouts.}

Although cinnamaldehyde incorporated SPI coated OPP/PE films showed minimum inhibitory effect in the agar diffusion method, it was capable of controlling the total mesophilic microbial count on sprouts stored in coated OPP/PE packages. Since cinnamaldehyde is a high volatile substance it may easily evaporate into the head space of the packages than diffuse into the agar medium. Figure 1 shows the effect of OPP/PE films coated with SPI containing different concentrations of cinnamaldehyde on total microorganism count of radish, alfalfa, and broccoli sprouts. Total number of CFUs of mesophilic microorganisms extracted from the sprout samples were used as the indicator of the antimicrobial effectiveness of cinnamaldehyde incorporated SPI coated OPP/PE packages. In the control samples where the radish, alfalfa, and broccoli sprouts were stored in OPP/PE, plastic box and SPI coated OPP/PE film packages, the total mesophilic microbial count increased over $6.5 \mathrm{log} \mathrm{CFU} / \mathrm{g}$. A similar pattern was observed in the low concentrations of cinnamaldehyde-coated packages. However, the mesophilic microbial population of sprouts stored in the OPP/PE film packages coated with SPI containing $1.0 \%$ and $1.2 \%$ cinnamaldehyde showed a significant reduction in all types of sprouts. The sensory qualities of the sprouts stored in cinnamaldehyde-coated packages were also at a satisfactory level until the end of the storage period compared to the control. In addition, due to intrinsic characteristics of cinnamaldehyde such as flavor, fragrance, and volatile compounds, the contents of the packages imparted a fresh odor when opened.

Physical and mechanical properties. Addition of cinnamaldehyde significantly $(p<0.05)$ affected the film properties. Figure 2 shows the effect of cinnamaldehyde on properties of the SPI films. TS of the cinnamaldehyde supplemented films increased with an increasing concentration of cinnamaldehyde incorporated into the film. In contrast, E\% decreased at higher concentrations of cinnamaldehyde. These results confirmed those of Kim et al. (9). When OPP/PE films were coated with SPI solutions supplemented with different concentrations of cinnamaldehyde, a slight reduction in TS, E\% was observed (Fig. 3). WVP of the SPI-cinnamaldehyde film and that coated onto OPP/PE films decreased as concentration of cinnamaldehyde increased (Fig. 3). Rojas-Graü et al. (26) found that incorporation of cinnamaldehyde $(0.5 \%, \mathrm{w} / \mathrm{w})$ reduced the WVP of alginateapple puree edible films. However, Kim et al. (9) observed that WVP of SPI films increases slightly at a cinnamaldehyde concentration of $0.5 \%(\mathrm{v} / \mathrm{v})$, and reported that incorporation of cinnamaldehyde into SPI solution increases the viscosity of the solution resulting in higher standard deviation in the film thickness and WVP. WVP results of this study confirmed those of Han et al. (12); addition of cinnamaldehyde into polyamide coated LDPE film improved the water vapor barrier properties. Even though addition of $1.2 \%(\mathrm{v} / \mathrm{v})$ cinnamaldehyde into the SPI solution produced a significant effect on film properties, in general it did not affect the TS, E\%, and WVP of the original OPP/PE film properties. This implies that composite films developed by cinnamaldehyde coating can be used for packaging without significant changes in physical and mechanical properties. 
Table 1. Diameter of the Inhibition Zones of Escherichia Coli, Salmonella

Typhimurium, Bacillus Cereus, Enterobacter Sakazakii observed with different Concentrations of Cinnamaldehyde (unit:mm)

\begin{tabular}{cccccc}
\hline $\begin{array}{l}\text { Cinnamaldehyde } \\
\mathrm{v} / \mathrm{v})\end{array}$ & $(\%$, & E. coli & S. typhimurium & B. cereus & E. sakazakii \\
\hline \hline & & & & & \\
\hline 0.1 & $31.8 \pm 0.20$ & $28.1 \pm 0.23$ & $27.8 \pm 0.38$ & $24.2 \pm 0.28$ \\
0.2 & $33.4 \pm 0.10$ & $28.1 \pm 0.15$ & $28.2 \pm 0.40$ & $25.6 \pm 0.28$ \\
0.3 & $36.1 \pm 0.23$ & $31.9 \pm 0.87$ & $30.2 \pm 0.20$ & $27.5 \pm 0.14$ \\
0.4 & $36.7 \pm 0.25$ & $33.1 \pm 0.45$ & $32.3 \pm 0.10$ & $29.9 \pm 0.28$ \\
0.5 & $38.2 \pm 0.12$ & $35.6 \pm 0.46$ & $35.7 \pm 0.42$ & $34.0 \pm 0.42$ \\
\hline
\end{tabular}

Table 2. MIC (minimal inhibitory concentration) and MBC (minimal bactericidal concentration) of cinnamaldehyde against $E$. coli, $S$. typhimurium, B. cereus, and E. sakazakii.

\begin{tabular}{ccc}
\hline & MIC $(\%)$ & MBC $(\%)$ \\
\hline \hline E. coli & 0.40 & 0.50 \\
S. typhimurium & 0.40 & 0.50 \\
B. cereus & 0.40 & 0.50 \\
E. sakazakii & 0.40 & 0.60 \\
\hline
\end{tabular}

Table 3. Antimicrobial Effectiveness of Cinnamaldehyde (\%, v/v) Incorporated SPI Films and Cinnamaldehyde Incorporated SPI Coated

OPP/PE films as determined by agar diffusion. (unit:mm). ${ }^{1)}$, SPIcinnamaldehyde film; ${ }^{2)}$, SPI-cinnamaldehyde coated OPP/PE film, ${ }^{3)}$, clear zone beneath tested discs (diameter, $8 \mathrm{~mm}$ ) but no diffusion

\begin{tabular}{ccccccccc}
\hline $\begin{array}{c}\text { Conc. } \\
(\%, \\
\mathrm{v} / \mathrm{v})\end{array}$ & \multicolumn{2}{c}{ E. coli } & \multicolumn{2}{c}{ S. typhimurium } & \multicolumn{2}{c}{ B. cereus } & \multicolumn{2}{c}{ E. sakazakii } \\
\hline \hline 0.6 & 0 & 0 & 0 & 0 & 0 & 0 & 0 & 0 \\
0.8 & $16.1 \pm 0.30$ & $\mathrm{SC}^{3)}$ & $14.7 \pm 0.50$ & 8 & $16.6 \pm 0.36$ & 8 & $15.4 \pm 0.60$ & 8 \\
1.0 & $18.3 \pm 0.40$ & 8 & $15.3 \pm 0.41$ & 8 & $18.0 \pm 0.20$ & 8 & $16.6 \pm 0.32$ & 8 \\
1.2 & $20.1 \pm 0.11$ & 8 & $18.0 \pm 0.40$ & 8 & $19.5 \pm 0.50$ & 8 & $18.9 \pm 1.00$ & 8 \\
\hline
\end{tabular}


Table 4. Thickness and Antimicrobial Active Volumes of SPIcinnamaldehyde Film and OPP/PE film containing soy protein isolatecinnamaldehyde layer used in disc diffusion method. 1): Soy protein isolatecinnamaldehyde incorporated film; ${ }^{2)}$ : OPP/PE containing soy protein isolate-cinnamaldehyde layer: total thickness of film-OPP/2 PE $(60 \mu \mathrm{m}) ;{ }^{3)}$ : Amount of cinnamaldehyde (cinnamaldehyde density: $1.05 \mathrm{~g} / \mathrm{cm}^{3}$ ) in film disc; volume was calculated by film thickness $x$ film area $\left(0.004^{2} \mathrm{~m}^{2} \times \pi\right)$

\begin{tabular}{ccccc}
\hline \multirow{2}{*}{$\begin{array}{c}\text { Concentration of } \\
\text { cinnamaldehyde }(\%, \mathrm{v} / \mathrm{v})\end{array}$} & \multicolumn{2}{c}{$\begin{array}{c}\text { Thickness -SPI incorporated } \\
(\mu \mathrm{m})\end{array}$} & $\begin{array}{c}\text { Cinnamaldehyde amount } \\
\text { in film disc }\end{array}(\mu \mathrm{g})$ \\
\cline { 2 - 5 } & $\mathrm{SC}^{1)}$ & Coated-SC $^{2)}$ & $\mathrm{SC}$ & Coated-SC \\
\hline \hline 0.6 & $113 \pm 3.6$ & $25 \pm 0.1$ & $0.52 \pm 0.018$ & $0.026 \pm 0.026$ \\
0.8 & $112 \pm 8.4$ & $22 \pm 0.1$ & $0.69 \pm 0.042$ & $0.035 \pm 0.029$ \\
1.0 & $113 \pm 8.9$ & $30 \pm 0.3$ & $0.86 \pm 0.047$ & $0.043 \pm 0.013$ \\
1.2 & $111 \pm 4.7$ & $25 \pm 0.2$ & $1.04 \pm 0.023$ & $0.052 \pm 0.083$ \\
Mean & $112 \pm 6.7$ & $26 \pm 0.3$ & & \\
\hline
\end{tabular}

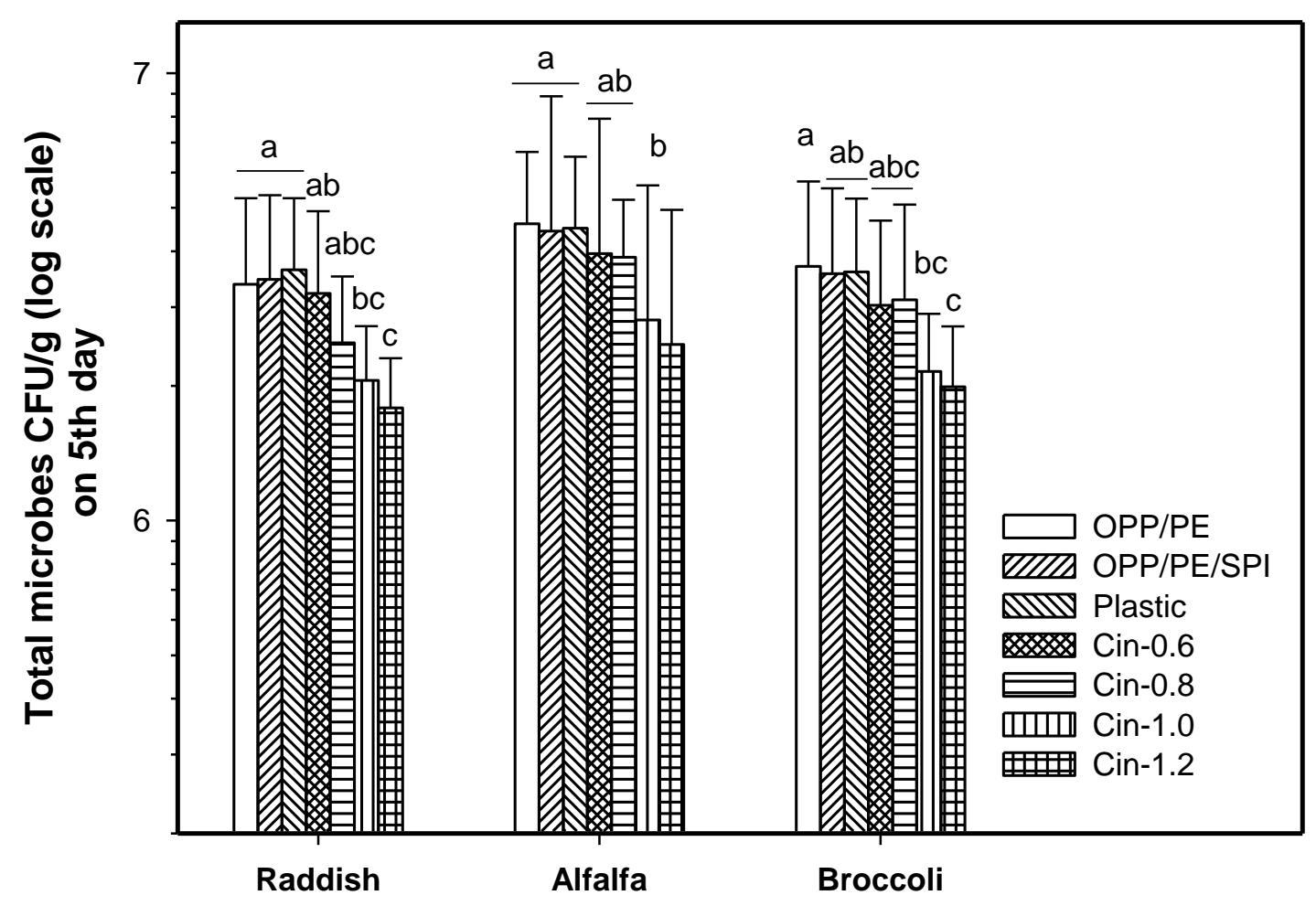

Figure 1. CFUs of Mesophilic Microbes Found in Sprouts (a, radish; b, broccoli; c, alfalfa) stored in OPP/PE packages coated with SPI solutions incorporated with different concentrations of cinnamaldehyde and control packages without coating and coated with SPI only 

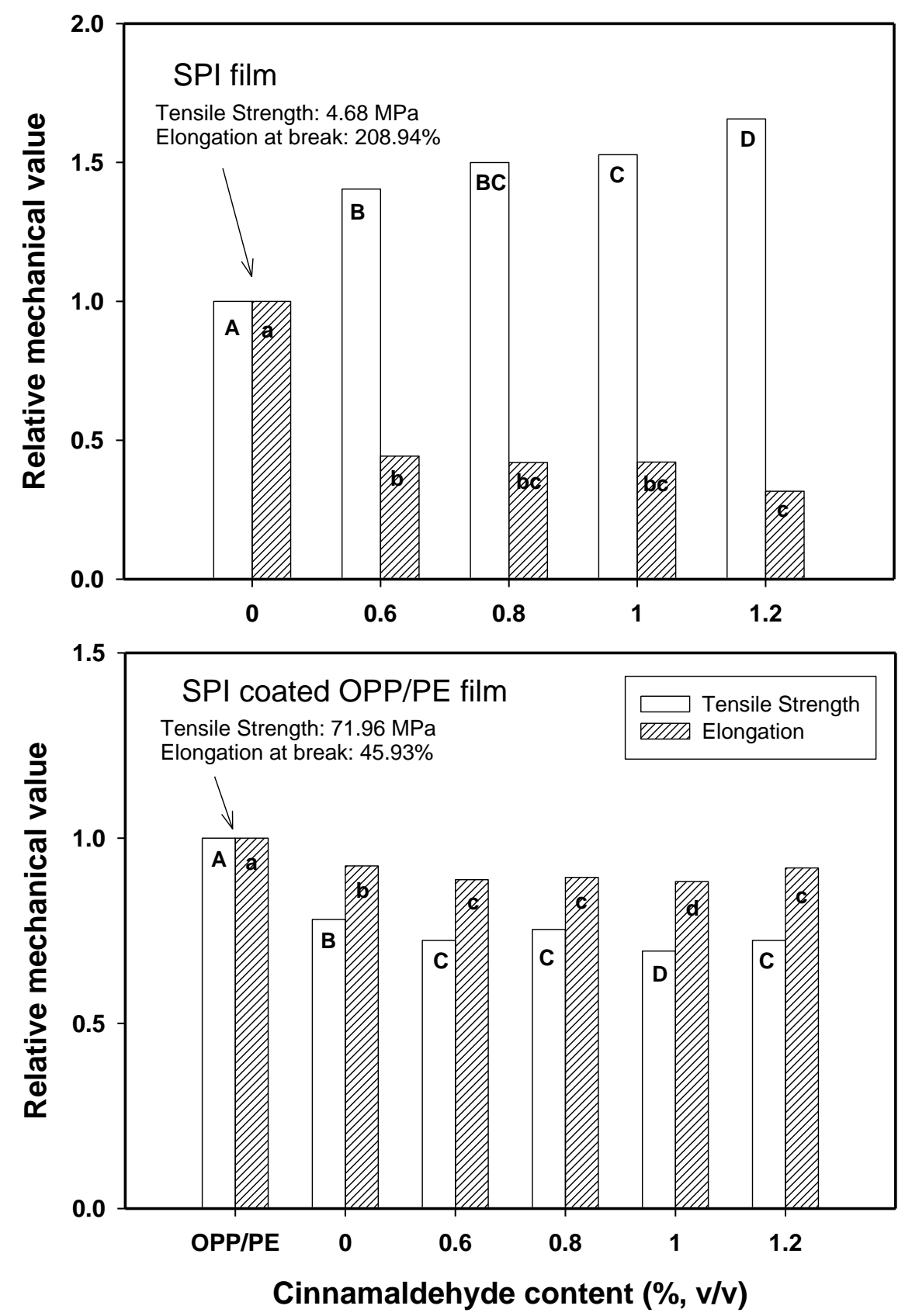

Figure 2. Relative Mechanical Values of SPI Films Supplemented with Different concentrations of cinnamaldehyde $(0,0.6,0.8,1.0$ and $1.2 \%, \mathrm{v} / \mathrm{v})$ and the control film without adding cinnamaldehyde (upper); OPP/PE films laminated with different concentrations of cinnamaldehyde $(0,0.6,0.8,1.0$ and $1.2 \%, v / v)$ incorporated SPI solutions and the control films without coating and coated by SPI only (down). 


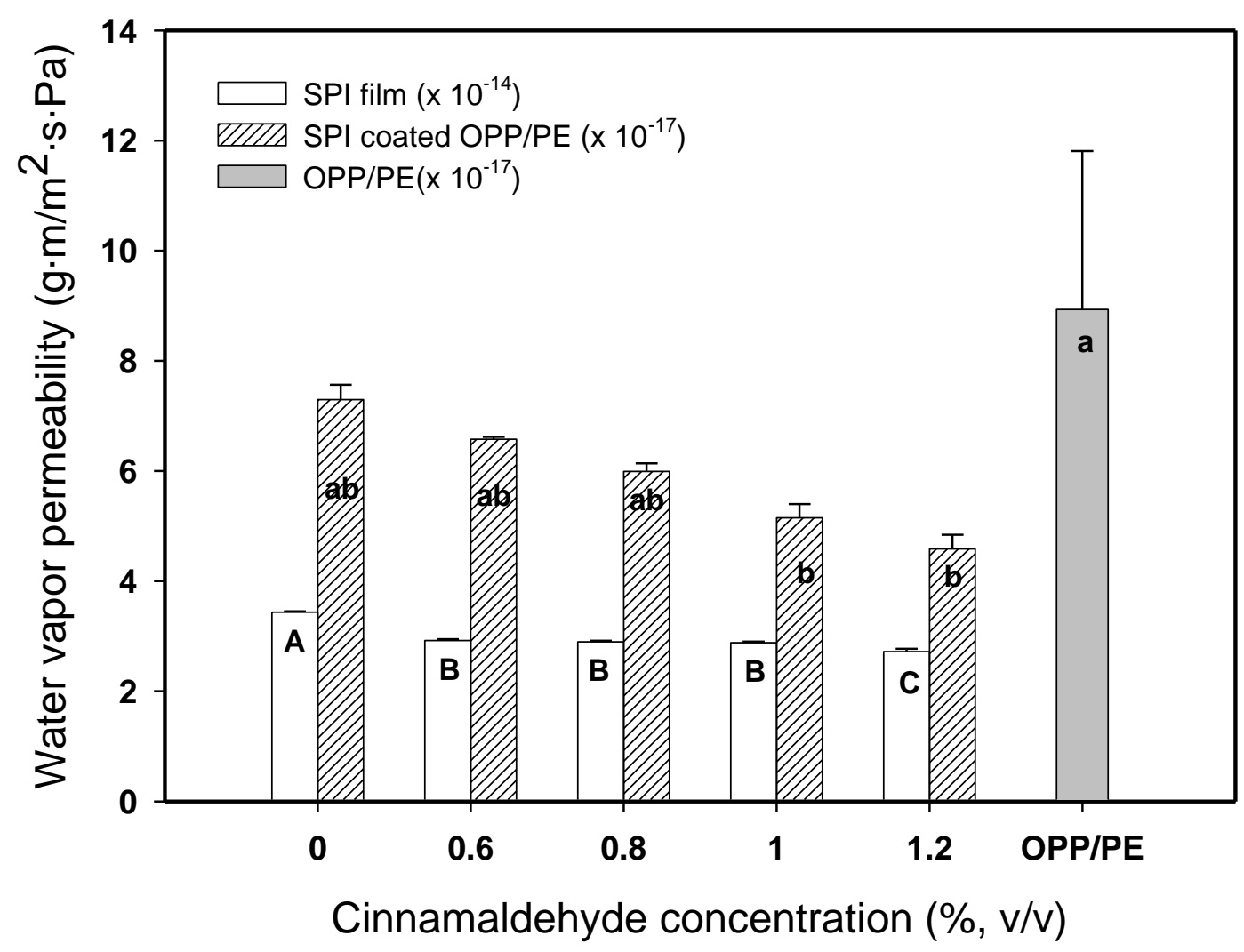

Figure 3. WVP of Cinnamaldehyde-containing Films. (a) WVP of SPI films supplemented with different concentrations of cinnamaldehyde and the control film without adding cinnamaldehyde. (b) WVP of OPP/PE films laminated with different concentrations of cinnamaldehyde incorporated SPI solutions and the control films without coating and coated with SPI only (control, OPP/PE; SPI, OPP/SPI/PE; SPI-C, OPP/SPI-cinnamaldehyde/PE).

Means with same letters are not significantly different at $(p<0.05)$.

\section{Acknowledgement}

This study was carried out with the support of Honam University

\section{References}

[1] Appendini P, Hotchkiss JH. Review of antimicrobial food packaging. Innov. Food Sci. Emerg. Technol. 3: 113-126 (2002)

[2] Siragusa GR, Dickson JS. Inhibition of Listeria monocytogenes on beef tissue by application of organic acids immobilized in a calcium alginate gel. J. Food Sci. 57(2): 293-296 (1992)

[3] Han JH. Antimicrobial food packaging. Food Technol-Chicago. 54 (3): 56-65 (2000)

[4] Balasubramanian A, Rosenberg LE, Yam K, Chikindas ML. Antimicrobial Packaging: Potential vs. Reality- A Review. J. App. Packaging Res. 3(4): 193-221 (2009)

[5] Krochta, JM, De Mulder-Johnston, C. Edible and biodegradable polymer films: challenges and opportunities. Food Technol-Chicago. 51: 61-74 (1997)

[6] Avena-Bustillos RJ, Krochta JM. Water vapor permeability of caseinate based edible films as affected by pH, calcium cross liking and lipid content. J. Food Sci. 58: 904-907 (1993)

[7] Ponce AG, Roura SI, Valle CE, Moreira MR. Antimicrobial and antioxidant activities of edible coatings enriched with natural plant extracts: In vitro and in vivo studies. Postharvest Biol. Tec. 49(2): 294-300 (2008)

[8] Rhim JW, Weller CL. Properties of formaldehyde adsorbed soy protein isolate films. Food Sci. Biotechnol. 9: 228-233 (2000) 
[9] Kim KM, Hanna MA, Weller CL, Cho SH, Choi SG. Characterization of cinnamaldehyde-supplimented soy protein isolate films. Food Sci. Biotechnol. 15: 631-634 (2006)

[10] Cagri A, Ustunol Z, Ryser ET. Antimicrobial Edible Films and Coatings. J. Food Protect. 67(4): 833-848 (2004)

[11] Cha DS, Chinnan MS Biopolymer-based Antimicrobial Packaging: A Review. CRC. Cr. Rev. Food Sci. 44(4): 223-237 (2004)

[12] Han J, Castell-Perez ME, Moreira RG. The influence of electron beam irradiation of antimicrobialcoated LDPE/polyamide films on antimicrobial activity and film properties. Lebensm-wiss Technol. 40: 1545-1554 (2007)

[13] Zagory D. Effect of post processing handling and packaging on microbial population. Postharvest Biol. Tec. 15: 313-321 (1999)

[14] Fett WF, Cooke PH. Reduction of Escherichia coli O157:H7 and Salmonella on laboratory- inoculated alfalfa seed with commercial citrus-related products. J. Food Protect. 66: 1158-1165 (2003)

[15] Martinez-Villaluenga C, Frias J, Gulewicz P, Gulewicz K, Vidal-Valverde C. Food safety evaluation of broccoli and radish sprouts. Food Chem. Toxicol. 46: 1635-1644 (2008)

[16] Park CM, Taormina PJ, Beuchat LR. Efficacy of allyl isothiocyanate in killing enterohemorrhagic Escherichia coli O157:H7 on alfalfa seeds. Int. J. Food Microbiol. 56: 13-20 (2000)

[17] Ouattara B, Simard RE, Piette G, Begin A, Holly RA. Diffusion of acetic and propionic acids from chitosan-based antimicrobial packaging films. J. Food Sci. 67 (1): 768-773 (2000)

[18] Barry AL, Thornsberry C. Susceptibility Tests: Diffusion Test Procedures. pp. 1117-1125. In: Manual of Clinical Microbiology. Lennette EH, Balows A, Hausler Jr WJ, Shadony HJ. (5 ${ }^{\text {th }}$ edition). American Society for Microbiology, Washington, DC, USA (1991)

[19] Oonmetta-aree J, Suzuki T, Gasaluck P, Eumkeb G. Antimicrobial properties and action of galangal (Alpinia galangal Linn.) on Staphylococcus aureus. Lebensm-wiss Technol. 39: 1214-1220 (2006)

[20] Lorian, V. Antibiotics in Laboratory Medicine. p.1. In: Disk susceptibility test Acar JF, Goldstein FW (eds.). Williams \& Walkins Awaverly, London, England (1995)

[21] ASTM. Standard test methods for water vapor transmission of materials. Vol. 4.06, pp. 697-704. In: Annual Book of ASTM Standards. American Society for Testing and Materials, Philadelphia, PA, USA (1995).

[22] Matan N, Rimkeeree H, Mawson AJ, Chompreeda P, Haruthaithanasan, V, Parker M. Antimicrobial activity of cinnamon and clove oils under modified atmosphere conditions. Int. J. Food Microbiol. 107: 180-185 (2006)

[23] Seydim AC, Sarikus G. Antimicrobial activity of whey protein based edible films incorporated with oregano, rosemary and garlic essential oils. Food Res. Int. 39: 639-644 (2006)

[24] Pranoto Y, Rakshit SK, Salokhe VM. Enhancing antimicrobial activity of chitosan films by incorporating garlic oil, potassium sorbate and nisin. Lebensm-wiss Technol. 38: 859-865 (2005)

[25] Lee JW, Son SM, Hong SI. Characterization of protein-coated polypropylene films as a novel composite structure for active food packaging application. J. Food Eng. 86: 484-493 (2008)

[26] Rojas-Graï MA, Avena-Bustillos RJ, Olsen C, Friedman M, Henika PR, Martin-Belloso O, Pan Z, McHugh TH. Effect of plant essential oils and oil compounds on mechanical, barrier, and antimicrobial properties of alginate-apple puree edible films. J. Food Eng. 81:634-641 (2007) 
International Journal of Bio-Science and Bio-Technology Vol.8, No.6 (2016) 